\title{
Influence of transparent exopolymer particles (TEP) on sinking velocity of Nitzschia closterium aggregates
}

\author{
Anja Engel*, Markus Schartau \\ Institut für Meereskunde Kiel, Universität Kiel, Düsternbrooker Weg 20, D-24105 Kiel, Germany
}

\begin{abstract}
Sinking velocities of more than 300 Nitzschia closterium aggregates were determined during roller table incubation using digital image analysis. To examine the influence of transparent exopolymer particles (TEP) on aggregate settling speed, 3 experiments with different ratios of TEP to cell volume concentration were conducted. The results showed that, for $N$. closterium aggregates without TEP, sinking velocity $(U)$ was significantly related to the equivalent spherical diameter (ESD) of the aggregates, yielding $U\left(\mathrm{~cm} \mathrm{~s}^{-1}\right)=1.89(E S D, \mathrm{~cm})^{0.55}$ The higher was the specific TEP content of an aggregate, the lower was the sinking velocity and the less pronounced was the size versus velocity relationship. Excess densities $(\Delta \rho)$ of aggregates were derived from velocity measurements and 3dimensional fractal dimensions (D3) of aggregates were calculated from scaling properties of $\Delta p$. Values for D3 never exceeded 2 and fit well to values of the 2-dimensional fractal dimension (D2) attained from image analysis.
\end{abstract}

KEY WORDS: Phytoplankton Aggregates - TEP - Nitzschia closterium - Sinking velocity - Fractal dimension

\section{INTRODUCTION}

In the pelagic environment the coagulation of suspended particles leads to the formation of macroscopic aggregates ('marine snow'), the sinking velocities of which can greatly exceed those of their individual components. Through their sedimentation below the surface mixed layer aggregates thus mediate the sequestration of photosynthetically fixed carbon to the ocean's interior. Since aggregation is primarily a function of particle size and concentration, the appearance of macroaggregates has commonly been observed during phytoplankton blooms (Alldredge \& Gotschalk 1989, Riebesell 1991, Kiørboe et al. 1994). Species of the genus Nitzschia are common in natural macroaggregates (Cabrini et al. 1992, Passow \& Alldredge 1994). The affinity of Nitzschia closterium to form aggregates has already been mentioned by Riley (1943). In laboratory experiments Monti et al. (1995) found that aged $N$. closterium were entangled with mucus into large stringers, similar to those found in the

·E-mail: aengel@ifm.uni-kiel.de
Adriatic Sea. Mucus particles are primarily composed of acidic polysaccharides (Leppard 1995). Alldredge et al. (1993) stained polysaccharide particles with the cationic dye Alcian Blue and defined transparent exopolymer particles (TEP) on the basis of this staining capacity. Since then TEP have been shown to be abundant in many marine ecosystems (Passow \& Alldredge 1994, Schuster \& Herndl 1995, Hong et al. 1997, Engel 1998). The importance of TEP for the formation of aggregates is assumed to be based upon their enhancement of coagulation efficiency (Passow et al. 1994. Logan et al. 1995). In contrast to solid components of 'marine snow' like diatoms, frustules or faecal pellets, TEP are supposed to have approximately the same density as the seawater in which they are produced (Alldredge \& Crocker 1995, MacIntyre et al. 1995). As a consequence TEP would enhance the formation but would reduce the sinking velocities of aggregates.

Various attempts have been made to measure the settling speed of 'marine snow' in situ as well as in the laboratory. One of the main challenges in gaining accurate results has been the handling of the fragile aggregates. Herein we present a simple method for 
the measurement of settling velocities of aggregates in vitro without perturbation due to isolation. Aggregates of Nitzschia closterium were formed on roller tables, and sinking rates were determined during incubation using digital image analysis. We tested the hypothesis that TEP concentration influences the sinking velocity of $N$. closterium aggregates by comparing results from 3 experiments ranging from low to high TEP content of aggregates.

\section{METHODS}

Theoretical considerations. The settling velocity $(U$, $\mathrm{cm} \mathrm{s}^{-1}$ ) of a particle in fluid results from the balance between gravity force $\left(F_{\mathrm{g}}\right)$ and drag force $\left(F_{\mathrm{d}}\right)$ :

$$
U=\left[2 g\left(\rho_{\mathrm{p}}-\rho_{\mathrm{fl}}\right) V /\left(C_{\mathrm{d}} \rho_{\mathrm{fl}} A_{\mathrm{p}}\right)\right]^{05}
$$

where the acceleration due to gravity $(g)$ is $981 \mathrm{~cm} \mathrm{~s}^{-2}$, $\rho$ is the density (in $\mathrm{g} \mathrm{cm}^{-3}$ ), either of the particle (p) or the fluid (fl), $V$ the particle volume, $C_{d}$ the dimensionless drag coefficient and $A_{p}$ the area of the particle perpendicular to the direction of the fall. For macroscopic aggregates the Reynolds numbers $(\mathrm{Re}=d U / v$, where $d$ is the particle diameter and $v$ is the kinematic viscosity) are typically $>0.5$ and the drag coefficient must be determined empirically (White 1974). The term $\rho_{p}-\rho_{i l}$ denotes the excess density $(\Delta \rho)$ of the particle. Excess densities of macroaggregates vary between $10^{-1}$ and

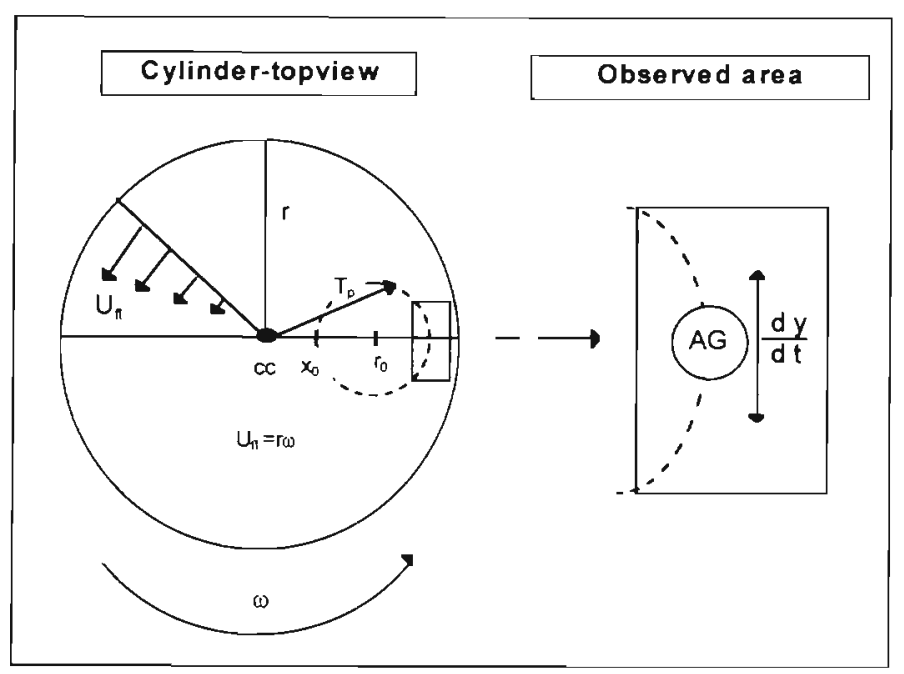

Fig. 1. Scheme of a rolling cylinder, topview. The axis (cc) of the cylinder is horizontal. Trajectories of aggregates formed on the roller table are ideally circular around the centre $r_{0}$. The cameraobserved area dissects the circular path of a particle, which is described by the trajectory vector $T_{p}$. In case of solid body rotation, the tangential velocity of the fluid $\left(U_{n}\right)$ is a function of distance $(r)$ to the centre $(c c)$ of the cylinder and of the radial velocity $(\omega)$. Under this condition, the settling speed of an aggregate (AG) can be calculated from changes in vertical position
$10^{-5} \mathrm{~g} \mathrm{~cm}^{-3}$, which is up to 4 orders of magnitude lower than $\Delta \rho$ of single phytoplankton cells (Alldredge \& Gotschalk 1988). This is due to the fact that aggregates are highly porous. Thus, the knowledge of the excess density of an aggregate is crucial to calculate its mass and consequently its settling speed

Aggregates readily form in cylindrical tanks rotated around their horizontal axis (Shanks \& Edmondson 1989). Such rotation produces a theoretical turbulencefree velocity field of the fluid (Tooby et al. 1977).

$$
U_{\mathrm{fl}}=\omega r
$$

where $U_{\mathrm{Il}}$ is the tangential velocity of the fluid ( $\mathrm{cm} \mathrm{s}^{-1}$ ), $\omega$ is the angular velocity of the fluid $\left(\mathrm{s}^{-1}\right)$ and $r$ is the radius (cm) of the cylinder (Fig. 1). The solid body rotation as described by Eq. (2) is achieved after a given spin-up time, determined as in Jackson (1994), during which the movement of the fluid propagates from the outer cylinder towards the centre. When solid body rotation is established, the trajectories of particles inside the cylinder are given by the balance between $F_{\mathrm{g}}$ and $F_{\mathrm{d}}$. Ideally, this results in closed orbital paths of particle trajectories, $\mathrm{T}_{\mathrm{p}}(t)=\left(p_{\mathrm{h}}, p_{\mathrm{v}}\right)$, where $p_{\mathrm{h}}$ and $p_{\mathrm{v}}$ are the horizontal and vertical components of the particle trajectory vector $\mathbf{T}_{\mathrm{p}}(t)$. If $\mathbf{X}_{0}=\left(x_{0}, 0\right)$ is the position at time $t=0$, then the components of the particle trajectories can be described as

$$
\begin{gathered}
p_{h}(t)=\left(x_{0}-r_{0}\right) \cos \omega t+r_{0} \\
p_{v}(t)=\left(x_{0}-r_{0}\right) \sin \omega t
\end{gathered}
$$

At the position $r_{0}$ the quotient $F_{\mathrm{g}} / F_{\mathrm{d}}$ is equal to the sinking velocity $\left(U_{0}\right)$ of the particle and the sinking velocity can be considered as:

$$
U_{0}=\omega r_{0}
$$

Particles that have differential settling velocities collide and probably adhere, leading to the formation of aggregates.

The simultaneous measurement of aggregate size $\left(>10^{-3} \mathrm{~cm}\right)$ and of the appropriate orbital path $\left(>10^{\circ} \mathrm{cm}\right)$ lacks accuracy due to the different orders of magnitude. However, during solid body rotation the sinking velocity $(U)$ of an aggregate can also be derived from its apparent velocity $\left(A U_{A G}\right)$

$$
U=U_{\mathrm{v}}+A U_{\mathrm{AC}}
$$

where $U_{v}$ is the vertical component of the fluid velocity at the radial distance $r$, and

$$
U_{\mathrm{v}}(r)=\omega r \cos \Phi
$$

If $x$ denotes the horizontal axis, which intersects the centre of the cylinder (cc), then geometrical considerations give (Fig. 2):

$$
x=r \cos \Phi
$$




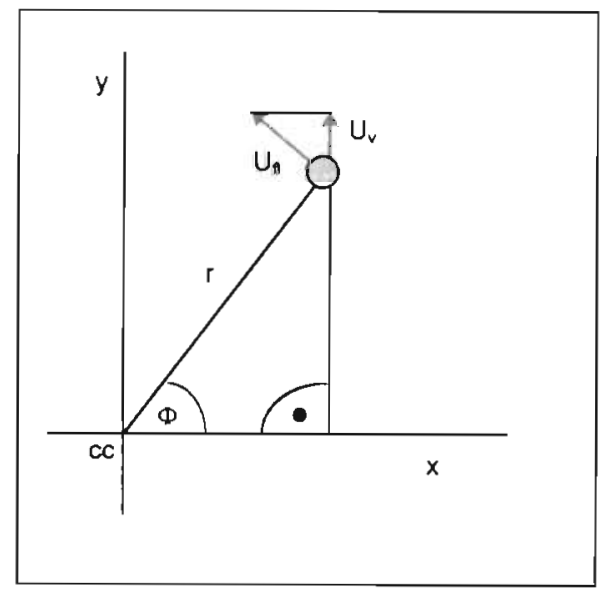

Fig. 2. Geometric illustration of Eq. (8). For $\Phi>0^{\circ}$ the vertical velocity $\left(U_{v}\right)$ of an object in the $x$ - $y$ plane is lower than the tangential velocity of the fluid $\left(U_{11}\right)$ and is given by $U_{\mathrm{v}}=\omega r \cos \Phi$. with $x=r \cos \phi$

The apparent velocity of the aggregate $\left(A U_{A G}\right)$ can be approximated from its vertical displacement in the $x-y$ plane with time:

$$
A U_{\mathrm{AG}}=-\Delta y / \Delta t
$$

To get an indication for the accuracy of the sinking velocity measurements we derived $\Delta \rho$ in our experiments from $U$ according to Eq. (1), calculated 3-dimensional fractal dimensions (D3) from scaling properties of $\Delta \rho$ and compared them to the 2-dimensional fractal dimensions (D2) we got from the image analysis.

The excess density $(\Delta \rho)$ of an aggregate is related to the density of the solid components $\left(\rho_{\mathrm{s}}\right)$ by (Alldredge \& Gotschalk 1988):

$$
\Delta p=\left\{\left[\rho_{\mathrm{s}}(1-p)\right]+\left(\rho_{\mathrm{f}:} p\right)\right\}-\rho_{\mathrm{i} 1}
$$

where $\rho_{\text {II }}$ is the density of the fluid and $p$ is the porosity, which is the volume fraction of the aggregate occupied by the fluid. The porosity of an aggregate is reduced if a part of the interstices is filled with TEP. It has been assumed that the density of TEP is equal to the density of the seawater in which they are produced (Alldredge \& Crocker 1995, MacIntyre et al. 1995). For aggregates that settle into deeper water of higher salinity, calculation of $\Delta p$ must take into account the TEP fraction inside an aggregate (Alldredge \& Crocker 1995). However, since salinity did not change during the experiments of this investigation, calculation of porosity can be simplified to:

$$
p=1-(S V / V V)
$$

Here $S V$ denotes the solid volume of the aggregate, which is given by the sum of volumes of the solid components, and $V V$ is the visible volume which is occu- pied by the aggregate. Solving Eq. (10) with Eq. (11) and assuming that $\rho_{\mathrm{s}}$ and $\rho_{\mathrm{ll}}$ are constant for a given type of particles, $\Delta \rho$ can be written as a function of the ratio $S V / V V$ :

$$
\Delta \rho=\left(\rho_{\mathrm{s}}-\rho_{\mathrm{fl}}\right)(S V / V V)
$$

The solid volume of an aggregate is related to size according to (Jiang \& Logan 1991):

$$
S V=a l^{\mathrm{D} 3}
$$

where $I$ is a typical size scale and D3 is the 3 -dimensional fractal dimension. So

$$
\Delta \rho \sim\left(a l^{\mathrm{D} 3}\right) /\left(b l^{3}\right)
$$

where $a$ and $b$ are constants, or:

$$
\Delta \rho \sim l^{\mathrm{D} 3-3}
$$

For marine aggregates ( $>0.5 \mathrm{~mm}$ ) D 3 has been found to be $<2$ (Logan \& Wilkinson 1990). Thus, Eq. (15) leads to an interpretation of an excess density that decreases with increasing aggregate size.

Diatom culture and empirical measurements. The pennate diatom Nitzschia closterium was isolated in November 1991 in the Kattegat by the Scandinavian Culture Centre for Algae and Protozoa (SCCAP). The algae were grown in continuous culture under $15^{\circ} \mathrm{C}$, $210 \mu \mathrm{mol} \mathrm{m} \mathrm{m}^{-2} \mathrm{~s}^{-1}$ photon flux in a $12 \mathrm{~h}$ light:12 h dark cycle and a salinity of 25 . Nutrient supply was based on f/2 medium (Guillard \& Ryther 1962) for Expt 1. Nitrogen limitation was found to enhance TEP production of $N$. closterium (Kraus 1997), so we chose 4 d of $N$-starvation for the culture used in Expt 2 and $10 \mathrm{~d}$ for the culture used in Expt 3.

TEP and cell volume concentrations within the aggregates were determined from samples taken after each experiment. Therefore the cylinders were carefully turned to one side, so that aggregates could settle to the bottom. Then the upper cylinder wall was removed, and aggregates were carefully isolated using a syringe with a $2 \mathrm{~mm}$ diameter needle.

TEP concentration was determined according to the colourimetrical method of Passow \& Alldredge (1995). Three replicates of $10 \mathrm{~cm}^{3}$ of culture and 1 to $5 \mathrm{~cm}^{3}$ of aggregate samples were filtered onto $0.4 \mu \mathrm{m}$ Nuclepore filters, stained with Alcian Blue and stored at $-21^{\circ} \mathrm{C}$ until analysis. For the microscopic observation of TEP abundance, semi-permanent slides were prepared (Passow \& Alldredge 1994). Measurements of the cell volume concentration were carried out with the Coulter Counter (Coulter Multisizer II) after appropriate $(<5 \%$ coincidence) dilution with $0.2 \mu \mathrm{m}$ (Nucleporel filtered seawater We chose the $100 \mu \mathrm{m}$ aperture, which gives accurate size measurements between 4 and $60 \mu \mathrm{m}$ equivalent spherical diameter (ESD). The sampling volume of the Coulter Counter was set to 
$2 \mathrm{~cm}^{3}$, and 4 replicates were measured of each sample. Since TEP cannot be detected by the Coulter Counter (Alldredge et al. 1993, authors' pers. obs.) it can readily been assumed that the volume concentration of particles $>4 \mu \mathrm{m}$ ESD was equal to the total cell volume concentration.

For comparison between the 3 experiments TEP concentration was related to the cell volume concentration ( $\phi)$. This yielded a TEP: $\phi$ ratio of $116 \pm 0.1 \mu \mathrm{g}$ Xanthan equivalent $\mathrm{cm}^{-3}$ of total cell volume for the culture of Expt 1 and $148 \pm 0.4 \mu \mathrm{g} \mathrm{Xan}$. equiv. $\mathrm{cm}^{-3}$ and $313 \pm 0.1 \mu \mathrm{g}$ Xan. equiv. $\mathrm{cm}^{-3}$ for Expts 2 and 3 . respectively (Table 1). However, in Expt 1 the microscopy showed no discrete Alcian Blue stained particles but adsorption of the dye to the cell surface. Tokuda (1969) found that the frustules of Nitzschia closterium were covered by a mucopolysaccharide sheath. Acidic polysaccharides that are bound a priori to the cell surface cannot be distinguished from TEP by the colourimetric method. So the TEP: $\phi$ ratio in the first experiment should be taken as a background value.

All experiments on the roller table were run for $24 \mathrm{~h}$ at a rotation speed of $0.77 \mathrm{rpm}$. We used 2 cylinders that were $30 \mathrm{~cm}$ in diameter, $15 \mathrm{~cm}$ in height and of about $10 \mathrm{dm}^{3}$ volume each. Aggregate position was observed with a Panasonic b/w video camera equipped with a $80 \mathrm{~mm}$ macro-lens placed in front of the cylinder. The observation area was $1.9 \times 3.1 \mathrm{~cm}$ in size and at a distance of $9.5 \mathrm{~cm}$ from the centre of the tank. The camera was connected to an S-VHS videorecorder (Panasonic AG-7350) via BNC-online and recorded for 5 min every 1 to $2 \mathrm{~h}$. A digital time code was placed on every video picture with a temporal resolution of $1 / 100 \mathrm{~s}$. Video pictures were digitised on a Macintosh Power PC $7500 / 100$ and analysed with the image program NIH-Image 160.ppc, a public domain program developed at the US National Institute of Health. The optical resolution of digitised pictures was $0.002 \mathrm{~mm}^{2}$ pixel $^{-1}$ The following parameters of each aggregate were measured semi-automatically: topview area $(A)$, perimeter $(P)$, length of the major axis (major), length of the minor axis (minor), largest expansion in the horizontal direction ( $x$-ferret length),

Table 1. TEP and cell volume concentration ( $\phi)$ within aggregates formed during the 3 experiments with Nitzschia clostenum

\begin{tabular}{|c|c|c|c|c|}
\hline & Unit & Expt 1 & Expt 2 & Expt. 3 \\
\hline $\begin{array}{l}\text { Cell volume } \\
\text { concentration }\end{array}$ & ()) $\mathrm{cm}^{3} \mathrm{dm}^{-3}$ & $65.0 \pm 8.69$ & $26.5 \pm 2.33$ & $18.6 \pm 2.04$ \\
\hline TEP & $\mu g$ Xan equiv. $\mathrm{dm}^{-3}$ & $7456 \pm 89$ & $4731 \pm 5.8$ & $4634 \pm 229$ \\
\hline TE:P:O & $\mu g$ Xan. equiv. $\mathrm{cm}^{-3}$ & $115 \pm 15$ & $179 \pm 17$ & $249 \pm 30$ \\
\hline
\end{tabular}

largest expansion in the vertical direction ( $y$-ferret length) and position in the $x$ - $y$ plane.

The visible volume of each aggregate ( $V V$ ) was calculated as the volume of an equivalent ellipsoid. The area perpendicular to the direction of fall was calculated as the maximum cross-sectional area $\left(A_{p}\right)$ either of a prolate or of an oblate ellipsoid. The aggregate was assumed to be prolate for $y$-ferret length $>x$-ferret length and $A_{p}$ was calculated according to:

$$
\left.A_{p}=\pi \text { (minor }\right)^{2} / 4
$$

Otherwise the aggregate more closely resembled an oblate ellipsoid, and $A_{p}$ was calculated from:

$$
\left.A_{p}=\pi \text { (major }\right)^{2} / 4
$$

The vertical velocity component $\left(U_{v}\right)$ of the fluid was calculated as the mean of the velocities $U_{v}\left(x_{1}\right)$ and $U_{\mathrm{v}}\left(x_{2}\right)$ at the start and end position of each aggregate path. Strictly speaking this holds only if the aggregate is exactly on a circular trajectory. To be safe we ensured that $\Delta x / \Delta t \ll \Delta y / \Delta t$ or at least $\Delta x / \Delta t<0.05$ $\Delta y / \Delta t$. From Eq. (5) it follows that the sinking velocity of a particle inside the cylinder may not be larger than $\omega r_{\mathrm{max}}$ otherwise the particle hits the wall of the cylinder and no 'free fall' can be measured. An observation area at the periphery of the tank was chosen to measure the higher sinking speeds of larger aggregates also.

The density of the fluid was calculated from temperature and salinity data according to the UNESCOscript of 1981 .

\section{RESULTS}

Visible aggregates appeared in each roller table incubation after 2 to $3 \mathrm{~h}$ (Fig. 3). Consistent with the TEP: $\phi$ ratios of the cultures, TEP: $\phi$ ratios within the aggregates were lowest in Expt 1 yielding $115 \pm 15 \mu \mathrm{g}$ Xan. equiv. $\mathrm{cm}^{-3}$, medium in Expt 2 with $179 \pm 17 \mu \mathrm{g}$ Xan. equiv. $\mathrm{cm}^{-3}$ and highest in Expt 3 with $249 \pm 30 \mu \mathrm{g}$ Xan. equiv. $\mathrm{cm}^{-3}$ (Table 1 ).

Size, shape and settling velocities of more than 300 aggregates were determined. The size of all measured aggregates ranged from 0.6 to $10 \mathrm{~mm}$. Between the 3 experiments, shape and size of aggregates varied and are shown for times 5 and $10 \mathrm{~h}$ of incubation in Table 2. Aggregates of Expts 2 and 3, which had higher TEP: $\phi$ ratios, were more elongated than those of Expt 1.

Sinking velocities of all aggregates ranged from 0.34 to $1.63 \mathrm{~cm} \mathrm{~s}^{-1}$ (or 301 to $1412 \mathrm{~m} \mathrm{~d}^{-1}$ ). Sinking velocities ( $U, \mathrm{~cm}$ $\mathrm{s}^{-1}$ ) of Nitzschia closterium aggregates 


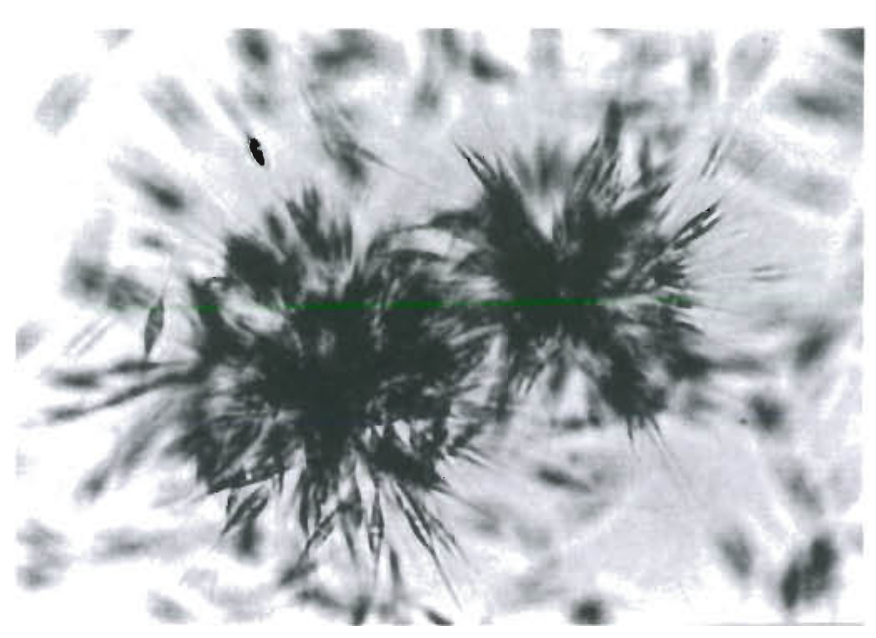

Fig. 3. Microaggregates of Nitzschia closterium formed during Expt 1. Cells stick directly to each other without TEP

without TEP (Expt 1) increased significantly with size $(E S D, c m)$ following a power law function:

$$
U=1.89(\mathrm{ESD})^{0.55}
$$

$\left(r^{2}=0.68, n=139, p<0.0001\right)$ (Fig. 4). Less pronounced yet still significant $(p<0.001)$ was the relationship between size and sinking velocity for aggregates of Expt 2. While for the smaller aggregates $(<3 \mathrm{~mm}$ ) a value of $U=0.72 \pm 0.19 \mathrm{~cm} \mathrm{~s}^{-1}$ was equal to the settling speed of smaller aggregates in Expt 1, the larger ones $(>3 \mathrm{~mm})$ settled more slowly $\left(U=0.89 \mathrm{~cm} \mathrm{~s}^{-1}\right)$ than those of Expt $1\left(U=1.26 \pm 0.23 \mathrm{~cm} \mathrm{~s}^{-1}\right)$. Sinking velocities were not related to size for aggregates of Expt 3 containing the highest TEP fraction. In contrast, the smaller aggregates $(<3 \mathrm{~mm})$ were found to settle at approximately the same speed $\left(0.63 \pm 0.15 \mathrm{~cm} \mathrm{~s}^{-1}\right)$ as those $>3 \mathrm{~mm}$ diameter $\left(0.69 \pm 0.08 \mathrm{~cm} \mathrm{~s}^{-1}\right)$.

To calculate $\Delta p$ according to Eq. (1), we used White's (1974) empirically derived formula for the drag coefficient at higher Reynolds numbers, because the Reynolds numbers we derived for aggregates from measurements of velocity, size and fluid viscosity

Table 2. Size and shape of aggregates formed during roller table incubation. Given are the mean values (median) of data obtained from Expts 1 to 3 after 5 and $10 \mathrm{~h}$ of incubation (VV: visible volume of an aggregate; Min.: Maj.: ratio of minor axis to major axis of an aggregate)

\begin{tabular}{|lcccccc|}
\hline & \multicolumn{2}{c}{ Expt 1 } & \multicolumn{2}{c}{ Expt 2 } & \multicolumn{2}{c|}{ Expt 3 } \\
& 5 & 10 & 5 & 10 & 5 & 10 \\
\hline $\mathrm{n}$ & 29 & 24 & 9 & 29 & 12 & 26 \\
Major $(\mu \mathrm{m})$ & 1238 & 1842 & 1053 & 1922 & 1119 & 2032 \\
VV $\left(\mathrm{mm}^{3}\right)$ & 0.44 & 1.8 & 0.27 & 1.6 & 0.21 & 1.3 \\
Min.:Maj. & 0.70 & 0.72 & 0.66 & 0.66 & 0.54 & 0.54 \\
\hline
\end{tabular}

exceeded the threshold value of 0.5 for Stokes settling in every case (Fig. 5)

Excess densities of measured aggregates covered 2 orders of magnitude and ranged from $8.8 \times$ $10^{-2}$ to $9.5 \times 10^{-4} \mathrm{~g} \mathrm{~cm}^{-3}$. In each experiment $\Delta \rho$ decreased with size of aggregates (Fig. 6). On the basis of Eq. (15) a power law function for $\Delta \rho=a l^{b}$
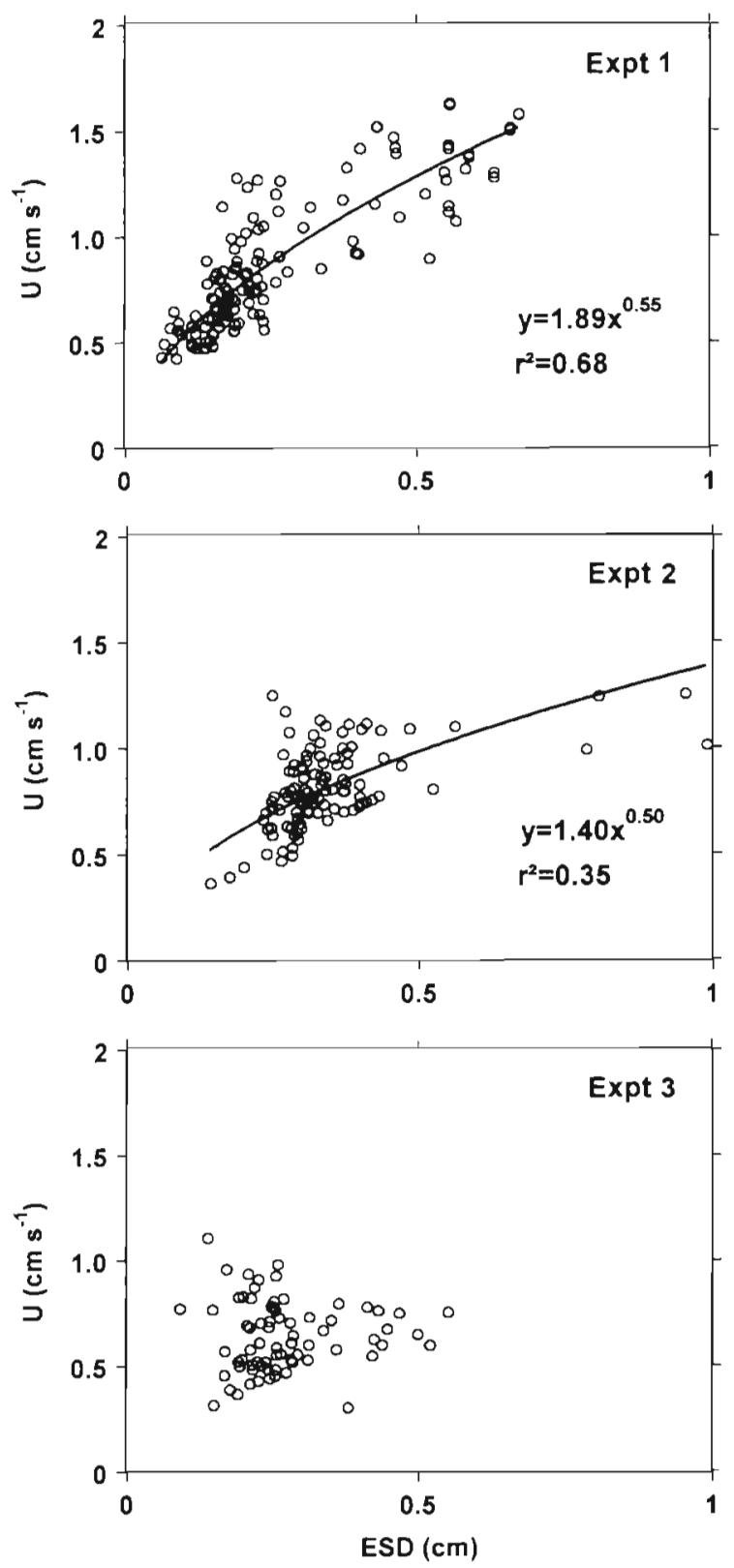

Fig. 4. Relation between sinking velocity $\left(U, \mathrm{~cm} \mathrm{~s}^{-1}\right)$ of Nitzschia closterium aggregates and the equivalent spherical diameter (ESD, cm). Sinking velocity of aggregates without TEP (Expt 1) was highest and increased with size following a power law function $(n=139, p<0.0001)$. Correlation between $U$ and ESD was less pronounced in Expt $2(n=112, p<0.001)$ and absent in Expt 3 ( $\mathrm{n}=74$, ns) 


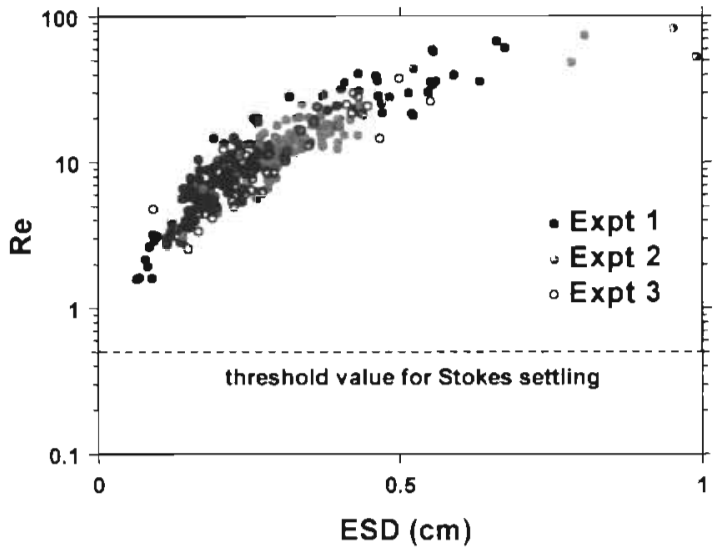

Fig. 5. Reynolds numbers (Re) of Nitzschia closterium aggregates, calculated from size, sinking velocity and fluid viscosity data, exceeded the threshold value of 0.5 for Stokes settling and increased with the equivalent spherical diameter $(E S D, \mathrm{~cm})$ of the aggregates

was assumed with $l=$ major and $b=\mathrm{D} 3-3$. Decrease of $\Delta \rho$ with the major axis of aggregates was steepest for aggregates of Expt 3 and lowest for aggregates of Expt 1. Linear regression of $\log \Delta p$ versus $\log$ major yielded a slope of $b_{1}=-1.03 \pm 0.049, b_{2}=-1.27 \pm$ 0.073 and $b_{3}=-1.56 \pm 0.075$ for Expts 1, 2 and 3 . respectively.

Values of D3 for aggregates of Expts 1, 2 and 3 were $\mathrm{D} 3_{1}=1.97 \pm 0.049, \mathrm{D} 3_{2}=1.73 \pm 0.073$ and $\mathrm{D} 3_{3}=1.44 \pm$ 0.075 , respectively. Therefore, the assumption D $3<2$ was confirmed for aggregates of Nitzschia closterium. For an ideal, infinite fractal, D3 equals the 2-dimensional fractal dimension (D2) if D3 $<2$ (Meakin 1988). Hence, the comparison of values of D3 and D2 can be used to test whether D3 derived from sinking velocity measurements are reliable. As D3 expresses the scaling relationship between length and solid volume of an aggregate, D2 can be derived relating length to area according to (Kilps et al. 1994):

$$
A \sim 1^{\mathrm{D} 2}
$$

D2 of aggregates in our experiments was attained by calculating the slope of the linear regression, $\log (A)$

Table 3. Two- (D2) and 3-dimensional (D3) fractal dimensions of Nitzschia closterium aggregates (Expts 1 to 3) (CI: confidence interval ${ }_{i}$ : number of aggregates used for regression analysis)

\begin{tabular}{|c|c|c|c|c|c|c|c|}
\hline Expt & $n$ & D3 & $\begin{array}{c}\mathrm{CI}(95 \%) \\
\text { D3 } \pm\end{array}$ & $r^{2}$ & $\mathrm{D} 2$ & $\begin{array}{c}\mathrm{Cl}(95 \%) \\
\mathrm{D} 2 \pm\end{array}$ & $r^{2}$ \\
\hline 1 & 139 & 1.97 & 0.13 & 0.87 & 1.96 & 0.01 & 0.95 \\
\hline 2 & 112 & 1.73 & 0.19 & 0.73 & 1.72 & 0.01 & 0.87 \\
\hline 3 & 74 & 1.44 & 0.20 & 0.87 & 1.44 & 0.01 & 0.92 \\
\hline
\end{tabular}
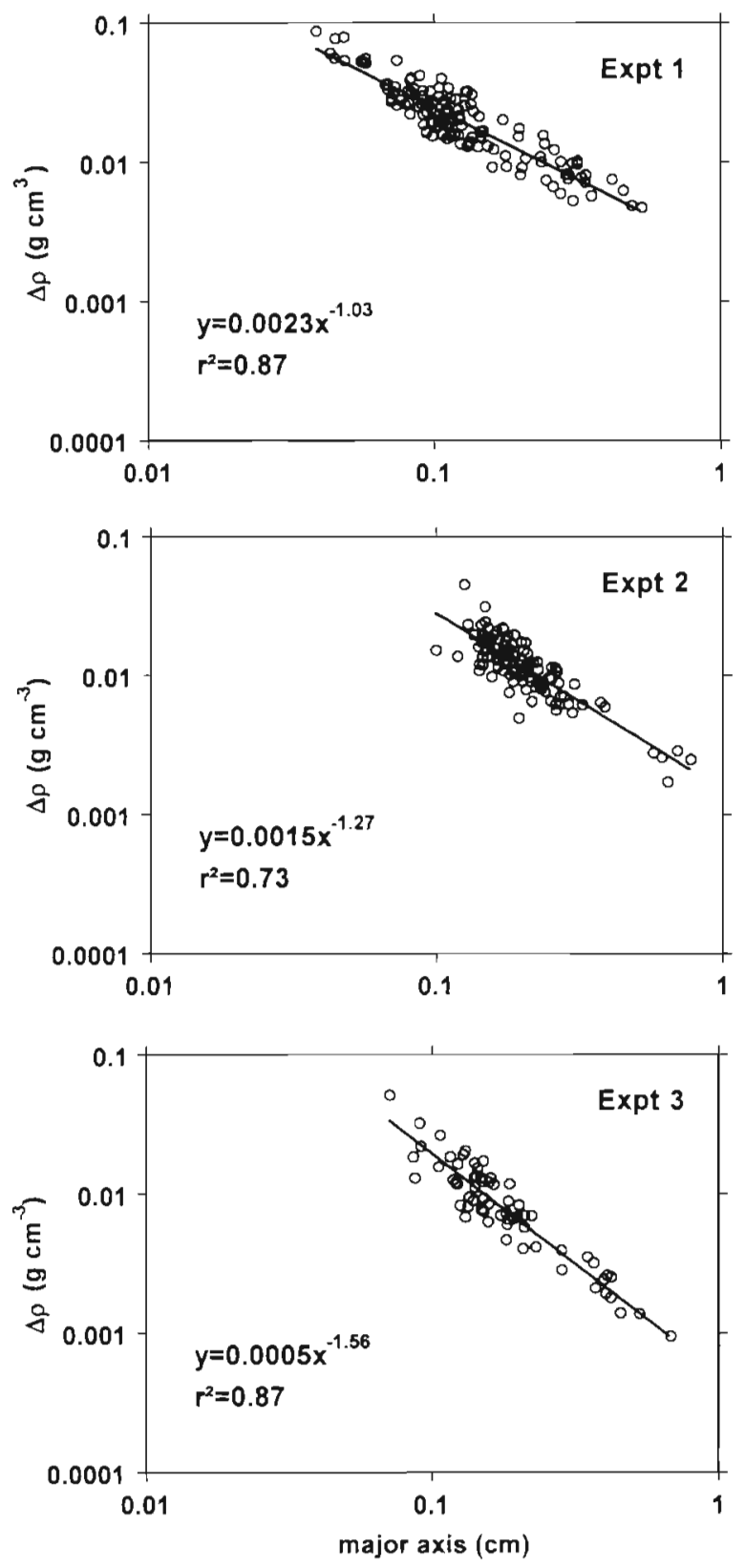

Fig. 6. Decrease of $\Delta \rho\left(\mathrm{g} \mathrm{cm}^{-3}\right)$ with the major axis $(\mathrm{cm})$ of Nitzschia closterium aggregates, without TEP (Expt 1), with medium TEP content (Expt 2) and with high TEP content (Expt 3)

versus log (major), whereby measurements of area and major were performed on the same aggregates as sinking velocity determinations. A $95 \%$ confidence interval was prescribed for D3 $=(b+3)$ and for D2 (Table 3$)$. For each experiment the value of D3 lies within the confidence interval of D2 and vice versa. Thus there were no statistically significant differences between the independently determined values of D3 and D2 $(p<0.05)$ 


\section{DISCUSSION}

Various previous studies have stressed the important role of marine aggregates in the vertical transport of particulate matter (Shanks \& Trent 1980, Asper et al. 1992). To calculate particle flux, information is needed on time scales of sedimentation as well as on the variability of settling velocity due to compositional changes. We have proposed a method, based on the determination of settling velocity inside the rolling cylinder via image analysis, to elucidate these parameters.

Aggregate excess density derived from velocity measurements was reproducible from the theoretical approach with fractal dimensions. So the presented method for the measurement of aggregate settling velocity is a suitable alternative, e.g. to settling chambers, for it does not require the isolation of aggregates and enables the simultaneous determination of size, shape and settling speed of a large number of aggregates.

The fractal properties of aggregates provide information on the size to volume scaling relationship and on the mechanisms of the coagulation process (Meakin 1991). Previously reported 2- and 3-dimensional fractal dimensions of marine snow are in the range of 1.39 to 1.81 (Logan \& Wilkinson 1990, Kilps et al. 1994, Chen \& Eisma 1995, Li \& Logan 1995), which corresponds to the fractal dimensions determined for Nitzschia closterium aggregates in Expt 2 and Expt 3 of the present study. We found that D3 of aggregates derived from velocity measurements were in good accordance with values of D2 determined by image analysis on their projection. This corroborates the applicability of image analysis for the examination of the fractal nature of aggregates, which is especially useful for the interpretation of in situ photographs.

Absolute values of sinking velocity of Nitzschia closterium aggregates determined during this study were higher than sinking velocities of diatom flocs measured in situ (Alldredge \& Gotschalk 1988). Lower sinking speed of natural aggregates may result from several façtors. First, natural flocs are more heterogeneous and may contain particles with a lower density than diatoms. Second, excess densities of $N$. closterium aggregates ranged from $10^{-2}$ to $10^{-4} \mathrm{~g}$ $\mathrm{cm}^{-3}$, which is up to 2 orders of magnitude higher than values obtained for natural flocs (Alldredge \& Gotschalk 1988, Diercks \& Asper 1997). Of course aggregates with high excess density can hardly achieve large size in the water column. They would rapidly settle out at small stages. The rolling cylinder is a closed system in which aggregation can continue as long as particle concentration is high enough to permit sufficient particle contact rates. The initial cell concentration of $N$. closterium cultures used here was much higher than natural abundance of diatoms. However, the primary goal of this investigation was to compare the relative effects of different TEP contents on aggregate settling velocity rather than the measurement of absolute sinking speeds applicable to nature. Sinking velocities determined for aggregates that were formed from natural water samples, using the same method as this study, were much lower and more comparable to previously reported values (Engel 1998). However, Lick et al. (1993) found that aggregates which are produced via differential settlement, like on the roller table, sink faster than aggregates produced by fluid shear.

Regarding the influence of TEP on the settling velocity of Nitzschia closterium aggregates, the 2 different methodological approaches gave consistent results. (1) Aggregates without TEP had higher values of fractal dimension, excess density and consequently higher settling velocities than aggregates with TEP. (2) The higher was the TEP: $\phi$ ratio of an aggregate, the lower were the values of D3, $\Delta \rho$ and $U$.

TEP apparently affect the vertical flux of particulate matter in 2 ways: on the one hand they enhance aggregate formation due to their high stickiness (Passow et al. 1994, Dam \& Drapeau 1995). On the other hand they reduce the settling velocity and consequently the export rates of aggregates by decreasing the excess density

Variability of aggregate settling velocity with size due to compositional differences is well documented in the literature (see Alldredge \& Silver 1988 for review). Previous studies which showed the existence of a relationship between aggregate size and settling velocity yielded different empirical functions, e.g. $U=0.67 d^{0.57}$ (Kajihara 1971), $U=50 d^{0.26}$ (Alldredge \& Gotschalk 1988) and $U=0.64 d^{1.25}$ (Lick et al. 1993). We found that incorporation of TEP into aggregates modulates the size versus velocity relationship and may even abolish it. This may be helpful for the interpretation of in situ observations, which showed that size of natural aggregates was not related to settling velocity (Diercks \& Asper 1997). However, more information concerning the temporal and spatial role of TEP within aggregates will be needed, e.g. for numerical ecosystem models which include the aggregation process for better estimates of the vertical biomass flux.

Acknowledgements. We are grateful to Uta Passow for her advice and good suggestions for the manuscript. We also thank Andreas Oschlies, John Dunne and 3 anonymous reviewers for valuable comments on the manuscript. The Scandinavian Center for Algae and Protozod (SCCAP) is gratefully acknowledged for providing the $N$. closterium culture and Michael Kraus for his assistance in diatom culturing. 


\section{LITERATURE CITED}

Alldredge AL, Crocker KM (1995) Why do sinking mucilage aggregates accumulate in the water column? In: Vollenweider RA, Rinaldi A (eds) Marine mucilages. Sci Total Environ 165:15-22

Alldredge AL, Gotschalk CC (1988) In situ settling behavior of marifie snow. Limnol Oceanogr 33(3):339-351

Alldredge AL, Gotschalk CC (1989) Direct observations of the mass flocculation of diatom blooms: characteristics, settling velocities and formation of diatom aggregates. DeepSea Res 36:159-171

Alidredge AL, Silver M (1988) Characteristics, dynamics and significance of marine snow. Prog Oceanogr 20:41-82

Alldredge AL, Passow U, Logan BE (1993) The abundance and significance of a class of large, transparent organic particles in the ocear. Deep-Sea Res 40(6):1131-1140

Asper VL, Deuser WG, Knauer GA, Lorenz SE (1992) Rapid coupling of sinking particle fluxes between surface and deep ocean waters. Nature 357:670-672

Cabrini M. Fonda Umani S, Honsell G (1992) Mucilaginous aggregates in the Gulf of Trieste (northern Adriatic Sea) analysis of the phytoplanktonic communities in the period June-August 1989. In: Vollenweider RA, Marchetti R, Viviani R (eds) Marine coastal eutrophication. Elsevier. Amsterdam, p 557-568

Chen S, Eisma D (1995) Fractal geometry of in situ flocs in the estuarine and coastal environments. Neth J Sea Res 33(2) $173-182$

Dam HG, Drapeau DT (1995) Coagulation efficiency, organicmatter glues and the dynamics of particles during a phytoplankton bloom in a mesocosm study. Deep-Sea Res II 42(1):11.1-123

Diercks AR, Asper VL (1997) In situ settling speeds of marine snow aggregates below the mixed layer - Black Sea and Gulf of Mexico. Deep-Sea Res I 44(3):385-398

Engel A (1998) Bildung, Zusammensetzung und Sinkgeschwindigkeiten mariner Aggregate. Ber Inst Meereskunde Kiel 300

Guillard RRL, Ryther JH (1962) Studies of the marine planktonic diatoms. I. Cyciotella nana (Hustedt) and Detonula confervacea (Cleve) Gran. Can J Microbiol 8:229-239

Hong Y, Smith WO, White AM (1997) Studies on transparent exopolymer particles (TEP) produced in the Ross Sea (Antarctica) and by Phaeocystis antarctica (Prymnesiophyceae). J Phycol 33:368-376

Jackson G (1994) Particle trajectories in a rotating cylinder: implications for aggregation incubations. Deep-Sea Res 41(3): $429-437$

Jiang Q. Logan BE (1991) Fractal dimensions of aggregates determined from steady state distributions. Environ Sci Technol 25:2031-2038

Kajihara M (1971) Settling velocity and porosity of large suspended particles. J Oceanogr Soc Jpn 27(4):158-162

Kilps JR, Logan BE. Alldredge AL (1994) Fractal dimensions of marine snow determined from image analysis of in situ photographs. Deep-Sea Res 41(8):1159-1169

Kiørboe T, Lundsgaard C, Olesen M. Hansen JLS (1994) Aggregation and sedimentation processes during a spring phytoplankton bloom: a field experiment to test coagulation theory. J Mar Res 52:297-323

Kraus M (1997) Zur Bildung von TEP (transparent exopolymer particles) in der Kieler Bucht. Master thesis, Universität Kiel

Leppard GG (1995) The characterization of algal and micro- bial mucilages and their aggregates in aquatic ecosystems. Sci Total Environ 165:103-131

Li X, Logan BE (1995) Size distributions and fractal properties of particles during a simulated phytoplankton bloom in a mesocosm. Deep-Sea Res 42(1):125-138

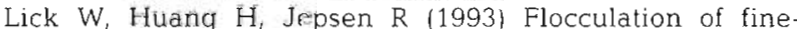
grained sediments due to differential settling. J Geophys Res 98(C6):10279-10288

Logan BE, Wilkinson DB (1990) Fractal geometry of marine snow and other biological aggregates. Limnol Oceanogr 35(1):130-136

Logan BE, Passow U, Alldredge AL, Grossart HP, Simon M (1995) Rapid formation and sedimentation of large aggregates is predictable from coagulation rates (half-lives) of transparent exopolymer particles (TEP). Deep-Sea Res II 42(1):203-214

Macintyre S, Alldredge AL, Gotschalk CC (1995) Accumulation of marine snow at density discontinuities in the water column. Limnol Oceanogr 40(3):449-468

Meakin P (1988) Fractal aggregates. Adv Colloid Interface Sci 28:249-331

Meakin P (1991) Fractal aggregates in geophysics. Rev Geophys 29(3):317-354

Monti M, Welker C, Dellavalle G, Casaretto L, Fonda Umani $S$ (1995) Mucous aggregates under natural and laboratory conditions: a review. In: Vollenweider RA, Rinaldi A (eds) Marine mucilages. Sci Total Environ 165:145-154

Passow U, Alldredge AL (1994) Distribution, size and bacterial colonization of transparent exopolymer particles (TEP) in the ocean. Mar Ecol Prog Ser 113:185-198

Passow U, Alldredge AL (1995) A dye-binding assay for the spectrophotometric measurement of transparent exopolymer particles (TEP) in the ocean. Limnol Oceanogr 40(7): $1326-1335$

Passow U, Alldredge AL, Logan BE (1994) The role of carbohydrate exsudation in the flocculation of diatom blooms Deep-Sea Res 40(2):335-357

Riebesell U (1991) Particle aggregation during a diatom bloom. II Biological aspects. Mar Ecol Prog Ser 69(3): $281-291$

Riley GA (1943) Physiological aspects of spring diatom flowerings. Bull Bingham Oceanogr Collect Yale Univ 8(4) $1-53$

Schuster S, Herndl GJ (1995) Formation and significance of transparent exopolymeric particles in the northern Adriatic Sea. Mar Ecol Prog Ser 124:227-236

Shanks AL, Edmondson EW (1989) Laboratory-made artificial marine snow: a biological model of the real thing. Mar Biol 101(4):463-470

Shanks AL, Trent JD (1980) Marine snow: sinking rates and potential role in vertical flux. Deep-Sea Res 27A:137-143

Tokuda H (1969) Excretion of carbohydrate by a marine pennate diatom. Nitzschia closterium. Rec Oceanogr Works Jpn 10:109-122. (As cited in Hoagland KD, Rosowski JR, Gretz MR (1993) Diatom extracellular polymeric substances: function, fine structure, chemistry and physiology. J Phycol 29:537-566)

Tooby PF, Wick GL, Isaacs JD (1977) The motion of a small sphere in a rotating velocity field: a possible mechanism for suspending particles in turbulence. J Geophys Res 82(15):2096-2100

UNESCO/ICES/SCOR/IAPSO (1981) Background papers and supporting data on the international equation of state of sea water. UNESCO Tech Pap Mar Sci 38:1-192

White FM (1974) Viscous fluid flow. McGraw-Hill, New York 